\title{
OBSERVATIONS ON THE AMERICAN WHITE PELICAN
}

MILES CONSTABLE, Environmental Protection, Room 210, 2nd Floor, Twin Atria 2, 4999 - 98 Avenue, Edmonton, Alberta. T6B 2X3

While doing a limnological survey on Primrose Lake, Alberta, I noted several interesting behavioural traits of the American White Pelican. I worked on the survey in 1980 and 1981 to characterize the limnology of Primrose and Cold Lakes. There is a large pelican colony that nests, in part, on a set of small islands in the north end of Primrose Lake (within the bombing range). The survey was conducted every second weekend from May through October, so I had ample opportunity to observe pelicans from close range.

The first behavioral trait that I noticed was that a line of flying pelicans would not cross over a boat, whether it was moving or stationary. Our water sampling transects frequently intersected lines of pelicans flying to or from the colony. Lines of pelicans flying back to the colony changed heading to avoid our stationary boat. After a while the behaviour intrigued

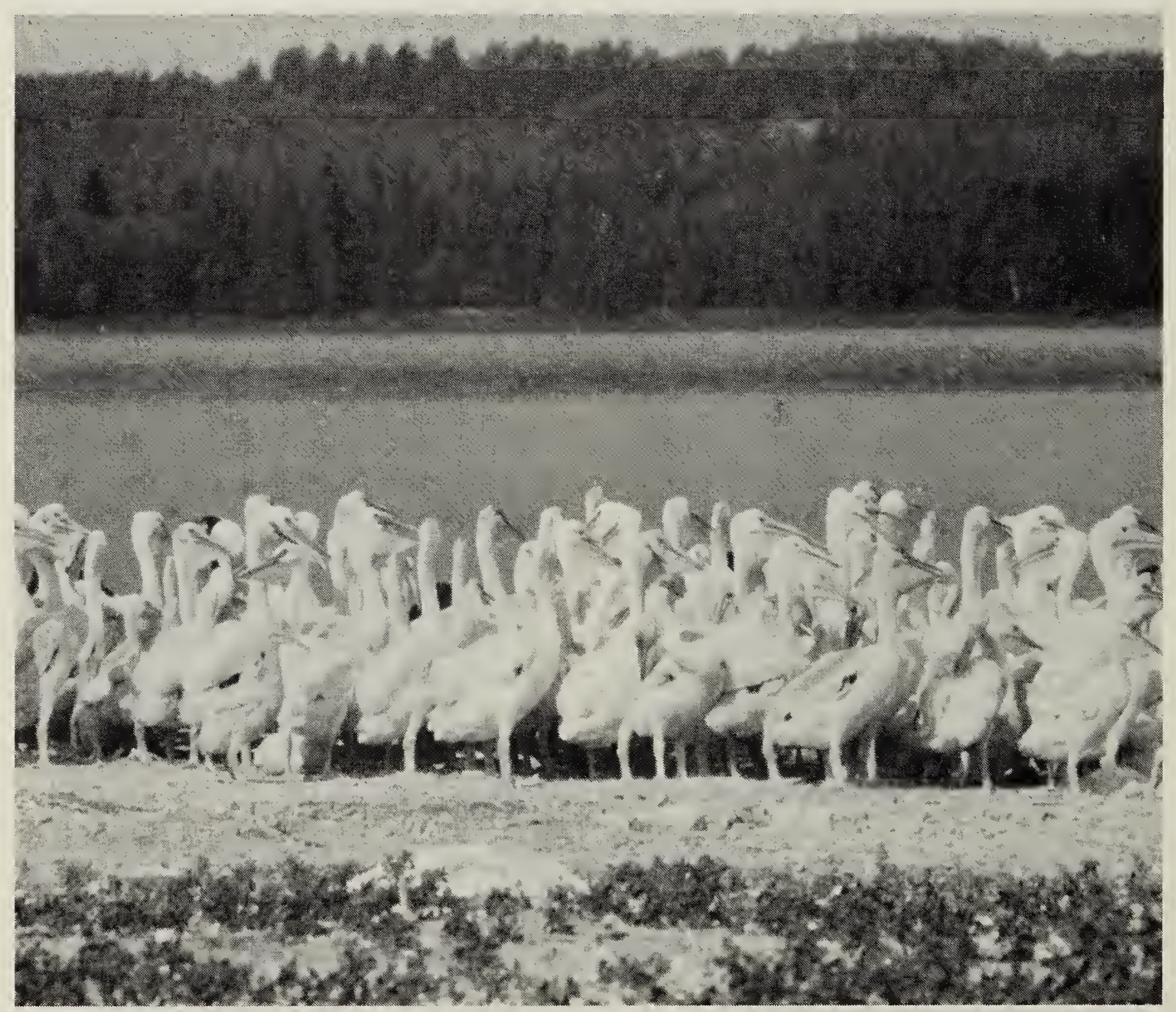

Pelican colony 
me, so 1 attempted to drive the boat under a line of flying pelicans. The birds actively avoided passing over the boat and this avoidance manoeuvring varied from a slight adjustment in heading if our boat was a fair distance away, to abrupt turns if our boat was very close to passing under them. One line of pelicans reversed course to avoid passing over the boat and went back around the boat to get to the colony. The reason for this avoidance was not clear, although hunting pressure outside the bombing range may be a cause. I cannot recommend this approach for other people as pelicans have enough problems with declining populations without even well-meaning people harassing them.

The second behavioural trait that I noticed was in how a line of flying pelicans coordinated their flying to gain altitude. The lead bird would start flapping to gain altitude; at roughly the point where the lead pelican started flapping the second would start flapping; and so on down the line. It appeared that the line of pelicans had reached a "step" in the air that they all had to "mount" as they came up to it. The result was an undulating line of pelicans that never failed to attract my attention.

Before the survey I had little contact with these lovely birds. After watching them for two summers on Primrose Lake I must say that they are some of my favourite birds to watch. Unfortunately for bird watchers, and fortunately for pelicans, they live in rather remote areas and it usually requires a boat to get close to them. I hate boats.

Anybody who has been around the woods knows that morning smells one way, high noon another, dusk still another, and night most different of all, if only because the skunks smell louder at night. Morning smells fresh and flowery and little - breezy, and dewy and spanking new. Noon smells hot and a little dusty and sort of sleepy, when the breeze has died and the heads begin to droop and anything with any sense goes off into the shade to take a nap. Dusk smells scary. It is getting colder and everybody is going home tired for the day, and you can smell the turpentine scars on the trees and the burnt-off ground and the bruised ferns and the rising wind... And in the night you can smell the fire and the warm blankets and the coffee a-boil, and you can even smell the stars. Robert Ruark, 1957. The Old Man and the Boy. Holt. 